\title{
ION ENERGY DISTRIBUTIONS FOR THE IDENTIFICATION OF ACTIVE SPECIES AND PROCESSES IN LOW PRESSURE HOLLOW CATHODE DISCHARGES
}

\author{
I. Tanarro ${ }^{1}$, V. J. Herrero \\ Instituto de Estructura de la Materia, CSIC, Serrano 123, 28006 Madrid, Spain \\ E-mail: itanarro@iem.cfmac.csic.es
}

\begin{abstract}
$\underline{\text { Abstract }}$
Energy distributions of ions generated in hollow cathode low pressures de discharges of different gases and gas mixtures containing $\mathrm{Ar}, \mathrm{H}_{2}, \mathrm{~N}_{2}, \mathrm{O}_{2}$ or $\mathrm{CH}_{4}$ are studied by quadrupole mass spectrometry. The ions are sampled through a small diaphragm in the grounded cathode. The measured distributions are mostly determined by the acceleration of ions in the sheath region between the negative glow and the cathode, displaying in general a narrow peak centred at energies close to the anode potential, but with specific features for the distinct ions. It is shown that information about ion production and sheath collision processes can be derived from the shapes of the different energy distributions. In some cases these distributions are used for the estimation of the relative abundance of ions with the same mass/charge ratio but different composition in complex gas mixtures.
\end{abstract}

Keywords: ion energy distribution, plasma sheath, dc discharge, hollow cathode discharge, ion kinetics, ion collisions, $\mathrm{Ar}, \mathrm{H}_{2}, \mathrm{~N}_{2}, \mathrm{O}_{2}$ and $\mathrm{CH}_{4}$ plasmas

PACS: 51.50.+v, 52.20.Hv, 52.25.Jm, 52.40.Kh, 82.33.Xj 


\section{Introduction}

Quadrupole mass spectrometry finds extensive application for the identification of ion and neutral species in reactive plasmas generated in low pressure glow discharges. In contrast with more selective detection techniques, often highly sensitive but specific for a few species like high resolution spectroscopic techniques [1-4] with lasers tunable in narrow spectral regions, mass spectrometry allows the detection of a large number of stable molecules [5,6], ions [7], and even radicals $[8,9]$.

Mass spectra of neutrals are usually affected by fragmentation at the ionization region of the detector, which may hinder an unambiguous assignment of the parent species. Several techniques have been developed to counter this problem, such as selective condensation in cryogenic traps [10], decomposition of multicomponent mass spectra using Bayesian probability theory [11] and ionization at the threshold energy [8,9], also known as appearance mass spectrometry [12,13], among others.

Mass spectrometry of ions coming directly from the discharge is not affected by fragmentation problems and the technique allows often the direct sampling of the actual ion composition in a given plasma and to obtain its ion energy distributions (IED). The analysis of ion translational energies can be crucial for the understanding of erosion and deposition processes in plasma assisted surface treatments $[14,15]$, and can provide very helpful information on kinetic processes taking place inside the plasma [16-20]. The specific energy distributions may be useful too for the identification of ions with the same mass/charge $(\mathrm{m} / \mathrm{q})$ ratio but different chemical compositions, which may be generated by different production mechanisms [21].

In recent works, we have investigated the concentrations of ions and neutrals in cold plasmas formed in low pressure hollow cathode DC discharges of air [22], $\mathrm{H}_{2}$ [23] and mixtures of $\mathrm{H}_{2}$ with traces of $\mathrm{N}_{2}$ and $\mathrm{CH}_{4}$ [24]. From the comparison of experimental data and model results, the key physicochemical processes determining the plasma composition were identified and preliminary explanations for some of the ion energy distributions measured were advanced [21-23]. In contrast with other type of plasmas (e. g. in RF discharges) where the shapes of the measured IED are affected by modulated electric fields, the IED at the cathode of DC plasmas are essentially determined by ion acceleration in the sheath, including eventual collisions in this region. In the present work, IED for DC plasmas with different gas precursors and discharge conditions are studied in more detail. In particular, new results on hollow cathode discharges of $\mathrm{Ar}, \mathrm{H}_{2}+\mathrm{Ar}$ and $\mathrm{H}_{2}+\mathrm{O}_{2}$ are presented here, as well as the effect of charge transfer reactions as gas pressure increases (in $\mathrm{Ar}$ and $\mathrm{H}_{2}$ plasmas). Especial attention is also paid to energy excesses observed in the IED, 
caused by electron impact dissociative ionization processes in $\mathrm{H}_{2}, \mathrm{~N}_{2}$ and $\mathrm{O}_{2}$ discharges, and by stripping reactions in $\mathrm{H}_{2}+\mathrm{N}_{2}$ and $\mathrm{H}_{2}+\mathrm{O}_{2}$ discharges.

In hollow cathode discharge reactors, the plasma can be roughly considered to be confined into the negative glow region $[25,26]$ (see figure 1). Outside this glow, electrons are scarce. The electric field in the negative glow, which fills most of the cathode volume, is close to zero, and ions inside the glow diffuse without a net gain of kinetic energy. The energy distributions, are then largely determined by the acceleration of the ions in the comparatively thin sheath region between the negative glow and the cathode, and are mostly characterized by a narrow maximum (FWHM $<2$ $\mathrm{eV}$ ) at an energy, $E_{m} \sim$ some hundreds $\mathrm{eV}$, close to that corresponding to the acceleration in the anode-cathode potential difference, which indicates that most ions move from the plasma edge towards the cathode through a largely collisionless sheath. In general, "wings" of variable magnitude can appear at the sides of the narrow peak at lower and higher energies [21]. The aim of this work has been to identify distinctive production and collision mechanisms leading to the various IED shapes, and to explore the possibility of using these distributions for the discrimination between ionic species with coincident $(\mathrm{m} / \mathrm{q})$ ratio but different atomic content.

\section{Experimental set-up}

The experimental set-up has been extensively described elsewhere [22,23] and only a brief account of the most relevant details is given here. A sketch of this experimental set-up for the detection of plasma ions is shown in figure 1. The reactor consists of a central anode and a grounded stainlesssteel cylindrical vessel (10 cm diameter, $34 \mathrm{~cm}$ length) acting as a cathode, with several vacuum flanges for gas input and output, and plasma sampling. It is continuously pumped by a turbomolecular pump and a dry pump to a background pressure of $10^{-5} \mathrm{~Pa}$. A butterfly vacuum valve at the exit of the reactor and various needle valves at the gas inputs were used for the control of the pressure and relative concentrations of the gases in the discharge mixture. A differentially pumped Balzers PPM421 Plasma Process Monitor (PPM) with an energy analyzer and a quadrupole mass filter was used for the detection of ions. Ions were extracted directly from the plasma through a $100 \mu \mathrm{m}$ diameter sampling orifice in the cathode, so that the measured ion energy is referenced to the ground potential. Within the PPM, ions are decelerated and focused with a set of electrostatic lenses onto the entrance of the energy analyzer formed by a semicylindrical capacitor [27] with an energy resolution of $0.3 \mathrm{eV}$. These ions are then mass-filtered with a quadrupole and focused on an electron multiplier. The PPM parameters were adjusted for optimum ion signal collection and energy resolution, and were maintained at these values during all the experiments, showing no 
problems with the potential settings. An electron bombardment ionizer placed before the energy analyzer is also available for the detection of neutrals, but it has not been used in these experiments.

Gas pressures $\sim 0.5-50 \mathrm{~Pa}$ were employed for plasma generation. Below the lower limit, the plasma extinguishes, and beyond the higher one, the pressure exceeds $\sim 10^{-4} \mathrm{~Pa}$ in the differentially pumped chamber of the mass spectrometer and precludes the use of the PPM detector. Precisely within these limits, two-body homogeneous reactions between ions and neutrals become relevant in the negative glow for the present reactor dimensions, and start giving rise to a rich and complex ion chemistry. Steady-state plasma currents $\sim 150 \mathrm{~mA}$ and voltages $\sim 250-450 \mathrm{~V}$ (depending of gas composition and pressure) in abnormal glow discharge conditions were maintained during the experiments, with the current stabilized power supply connected to the anode through a ballast resistance. An electron gun was used for plasma ignition. Electron temperatures and densities were measured with a double Langmuir probe and had typical values of $\mathrm{n}_{\mathrm{e}} \approx 10^{10} \mathrm{~cm}^{-3}$ and $\mathrm{T}_{\mathrm{e}}=3-8 \mathrm{eV}$ for the plasmas under study [22,23], assuming a Maxwell distribution. From charge density measurements, a rough estimation of absolute values of ion concentrations in the negative glow and ion fluxes to the cathode has been deduced in previous works for the diverse ion species $[22,23]$ under conditions of no significant charge-transfer collisions in the sheath.

\section{$\underline{\text { 3. Results and discussion }}$}

Figures 2.a and 2.b display the IED of the simplest plasmas studied in the present experiments. They correspond to non reactive atomic plasmas of $\mathrm{Ar}$, at $0.7 \mathrm{~Pa}$ and $4 \mathrm{~Pa}$ respectively. Energy shifts of the peaks for this and the other plasma precursors are mainly due to changes of the plasma conductivity with pressure, for a constant electric current value $(150 \mathrm{~mA})$ crossing the discharge and the ballast resistance. For the lower pressure, narrow peaks with $E_{m}$ close to the anode-cathode fall potential can be clearly seen for $\operatorname{Ar}^{+}(m / q=40)$ and $\operatorname{Ar}^{++}(m / q=20)$, which reflect the narrow velocity distribution of the ions in the cold plasmas under investigation. Note that doubly charged ions gain two times the energy of singly charged ions. For convenience, the energy distributions IED are expressed in terms of the reduced variable $E=E_{k i n} / q$, where $E_{k i n}$ is the kinetic energy at the cathode and $q$, the ion charge.

Most of the detected Ar ions cross the thin sheath region without energy loss, and give rise to the sharp peaks mentioned above. The very weak asymmetric low energy tails of $\mathrm{Ar}^{+}$and $\mathrm{Ar}^{++}$ are due to the detection of ions reaching the sampling orifice at the cathode wall with smaller energies or with incidence angles lower than $90^{\circ}$. An entirely different distribution, monotonically decreasing with growing $E$, is obtained for the higher pressure. In this case, virtually all $\mathrm{Ar}^{+}$ions 
reaching the detector have been decelerated in sheath collisions. The main energy loss mechanism is in this case symmetric charge exchange. $\mathrm{Ar}^{+}$ions leaving the negative glow are accelerated towards the cathode and transfer their charge, but not their translational energy, to neutral atoms in the sheath, these secondary ions are then accelerated from the point where they are formed and do not reach the energy corresponding to the full cathode fall potential. Depending on the gas pressure this process can be repeated several times in the sheath. An analytical expression for the resulting ion energy distribution in this type of collisional sheath was derived by Davis and Vanderslice [28] with a simple model assuming a linear potential fall between plasma and cathode and an average cross section for symmetric charge exchange over the collision energy range. Experimental measurements have repeatedly validated this simple model (see for instance [29,30]). The relevant parameter in the IED provided by the model of Davis and Vanderslice is the quotient between the sheath width, $S$, and the mean free path, $\lambda$. A fit of our experimental IED for a pressure of $4 \mathrm{~Pa}$ (figure 2.b) yields $S / \lambda=9$, which is a measure of the number of collisions in the sheath. This value is consistent with an average cross section of $\sim 4 \times 10^{-15} \mathrm{~cm}^{2}[31,32]$ and with a sheath width of $\sim 1.5$ $\mathrm{cm}$, which is reasonable for the conditions of our plasma. The shape of the IED for $\mathrm{Ar}^{++}$is much less distorted by the pressure increase, revealing that charge transfer processes in the sheath are much less efficient for the doubly charged ion, its average cross section being $\sim 7 \cdot 10^{-16} \mathrm{~cm}^{2}[28$, 33,34] for the range of ion energies involved; i.e., about six times smaller than that of $\mathrm{Ar}^{+}$. Note that the ratio of $\mathrm{Ar}^{+}$to $\mathrm{Ar}^{++}$is much larger for the higher pressure, due to the fact that the electron temperature decreases and thus the proportion of high energy electrons $(>50 \mathrm{eV})$ leading to $\mathrm{Ar}^{++}$ ionization is proportionally much smaller. Argon plasmas are commonly used in DC and RF sputtering systems, where their ion energy distributions are determinant for sputtering yields [35]. Therefore, the relation between ion energy and discharge pressure is of outstanding relevance. The role of $\mathrm{Ar}^{+}$ions and energetic neutrals in hollow cathode discharges, as well as the electric fields and the potential distributions, have been recently modelled by Baguer et al [25].

Cold plasmas dominated by hydrogen (or its isotopes) are significant in many areas of materials fabrication, in the plasma wall interaction of controlled fusion devices fuelled by deuterium and tritium, and also in astrophysics. The $\mathrm{H}_{3}{ }^{+}$ion, which is often dominant in $\mathrm{H}_{2}$ plasmas, is basic for the generation of a large number of molecules observed in the interstellar space [36]. In magnetically confined fusion reactors, the hot plasma core is separated from the walls by a cold plasma region where hydrogenic ions can participate in a rich heterogeneous chemistry $[24,37]$.

Figure 3 displays the energy distributions of ions with $m / q=1,2$ and 3 for the hollow cathode $\mathrm{H}_{2}$ discharges, at $2 \mathrm{~Pa}$ (figure 3.a) and $20 \mathrm{~Pa}$ (figure 3.b). The region around the main peak, 
which is important for the following discussion, has been enlarged in the insets. For the two pressures shown, $\mathrm{H}_{3}{ }^{+}(m / q=3)$ is the major ion. It is generated mostly in the negative glow by the efficient ion molecule reaction [38-40]:

$$
\mathrm{H}_{2}+\mathrm{H}_{2}^{+} \rightarrow \mathrm{H}_{3}^{+}+\mathrm{H} \quad \mathrm{k}_{1}=1.9 \times 10^{-9} \mathrm{~cm}^{3} \mathrm{~s}^{-1}
$$

Its rate constant is nearly independent of the gas temperature over a wide $\mathrm{T}$ range [30], including the present room temperature conditions [23]. Through this mechanism, $\mathrm{H}_{2}{ }^{+}$, initially produced by electron impact, is largely converted to $\mathrm{H}_{3}{ }^{+}$, even at comparatively low pressures [23,24]. Given the inefficient interaction of $\mathrm{H}_{3}{ }^{+}$with the dominant $\mathrm{H}_{2}$ molecules [38,39], most of the $\mathrm{H}_{3}{ }^{+}$ions cross the sheath region without perturbation and give rise to intense sharp peaks. This shape remains essentially unchanged in spite of the factor ten increase in pressure shown in figure 3.

$\mathrm{H}_{2}{ }^{+}(m / q=2)$ predominates only at pressures low enough to make the mean free path of the ions comparable or larger than the size of the negative glow. Under our experimental conditions this happens for pressures below $\sim 0.5 \mathrm{~Pa}$ [23], but at $2 \mathrm{~Pa}$ (figure 3.a) the concentration of $\mathrm{H}_{2}^{+}$is already much lower than that of $\mathrm{H}_{3}{ }^{+}$, due mostly to reaction (1). A low energy wing, characteristic of efficient collisions in the sheath [38], becomes already appreciable in the IED of $\mathrm{H}_{2}{ }^{+}$at $2 \mathrm{~Pa}$. At $20 \mathrm{~Pa}$ (figure 3.b), the small amount of $\mathrm{H}_{2}{ }^{+}$ions that have not been transformed to $\mathrm{H}_{3}{ }^{+}$undergo symmetric change transfer collisions in the sheath, and the corresponding IED becomes a monotonic decreasing function of energy similar to that already described for $\mathrm{Ar}^{+}$(see figure 2.b). A fit of this distribution with the model of Davis and Vanderslice, also shown in figure 3.b leads to $S / \lambda=13$. This value is consistent with an average charge-exchange cross section of $\sim 8.5 \times 10^{-16}$ $\mathrm{cm}^{2}$ over the relevant energy range [38], and with a sheath width of $\sim 2 \mathrm{~cm}$.

The IED of the $\mathrm{H}^{+}$ion $(m / q=1)$ deserves special attention. $\mathrm{H}^{+}$ions can be generated in the hydrogen plasma by the processes $[39,41]$ :

$$
\begin{array}{ll}
\mathrm{H}+\mathrm{H}_{2}^{+} \rightarrow \mathrm{H}^{+}+\mathrm{H}_{2} & \mathrm{k}_{2}=6.4 \times 10^{-10} \mathrm{~cm}^{3} \mathrm{~s}^{-1} \\
\mathrm{H}+\mathrm{e} \rightarrow \mathrm{H}^{+}+2 \mathrm{e} & \mathrm{k}_{3}=6.50 \times 10^{-9} \times \mathrm{T}_{\mathrm{e}}^{0.49} \times \mathrm{e}^{-12.89 / \mathrm{Te}} \mathrm{cm}^{3} \mathrm{~s}^{-1} \\
\mathrm{H}_{2}+\mathrm{e} \rightarrow \mathrm{H}+\mathrm{H}^{+}+2 \mathrm{e} & \mathrm{k}_{4}=3.00 \times 10^{-8} \times \mathrm{T}_{\mathrm{e}}^{0.44} \times \mathrm{e}^{-37.73 / \mathrm{Te}} \mathrm{cm}^{3} \mathrm{~s}^{-1}
\end{array}
$$

Where the rate coefficients for electron impact ionization are expressed in terms of the electron temperature, $\mathrm{T}_{\mathrm{e}}(\mathrm{eV})$, for an assumed Maxwell distribution of electron energy. For the two discharge pressures considered in figure 3, double Langmuir probe measurements of $\mathrm{T}_{\mathrm{e}}$ yielded values of $6 \mathrm{eV}$ for $2 \mathrm{~Pa}$, and $3 \mathrm{eV}$ for $20 \mathrm{~Pa}$ [23]. At $2 \mathrm{~Pa}$ (figure 3.a), the energy distribution of $\mathrm{H}^{+}$is formed by a narrow maximum corresponding roughly to the anode-cathode voltage, and a broader peak extending $\sim 15 \mathrm{eV}$ toward higher energies. The source of this higher energy ions is reaction (4), which takes place through electron excitation from the ground state of $\mathrm{H}_{2}\left({ }^{1} \Sigma_{\mathrm{g}}{ }^{+}\right)$to dissociative 
states of the molecule. In particular, for the conditions of the discharge considered, the main contribution to reaction (4) is the excitation to the ${ }^{2} \Sigma_{\mathrm{u}}{ }^{+}$dissociative state, which leads to $\mathrm{H}^{+}$ions and $\mathrm{H}$ atoms in their electronic ground states, but with high kinetic energy, as shown in figure 4 . The most probable energy for the corresponding Franck Condon vertical transition is $~ 34 \mathrm{eV} \mathrm{[42],}$ which is reflected in the high activation energy of reaction (4). Experiments with electron beams [42-44] show that the $\mathrm{H}^{+}$ions generated in this process have broad energy distributions peaking at $\simeq$ $8 \mathrm{eV}$, i.e. the difference between the energy required for the Franck Condon transition and that of the free products of dissociation, $\mathrm{H}$ and $\mathrm{H}^{+},(\sim 18 \mathrm{eV})$ divided between the two particles. In the right panel of figure 4 we have represented for comparison our own results of figure 3.a and the $\mathrm{H}^{+}$ energy distribution from one of the beam experiments of van Brunt [45], corresponding to an electron energy of $75 \mathrm{eV}$ and to a scattering angle of $23^{\circ}$ with respect to the electron beam. For the case of the present low pressure discharge ( 2 Pa), many of these ions are not thermalized in the negative glow and reach the cathode with their "excess" energy, giving rise to the mentioned high energy maximum. Note that in spite of the smearing caused by the spread in scattering angles and electron energies within the plasma, the energy distribution of the $\mathrm{H}^{+}$ions reaching the detector reflects largely the Franck Condon dissociative ionization. The similitude between the IED of $\mathrm{H}^{+}$ ions from the bulk of the plasma and that of the beam experiments might be striking at first sight, but one must consider that the Franck Condon vertical transition imposes the most favorable energy and that the angular smearing is partly removed by the fact that only nascent ions moving roughly perpendicular to the cathode wall in the direction of the detector orifice will reach the detector after acceleration in the sheath. At the higher pressure (i.e. $\sim 20 \mathrm{~Pa}$ ), the electron temperature is lower (3 $\mathrm{eV}$ ) and the rate coefficient of reaction (4), which is the one producing the fast $\mathrm{H}^{+}$ions, decreases by three orders of magnitude; consequently the higher energy maximum in the corresponding IED disappears, as shown in figure 3.b. The higher pressure induces also a low energy tail with a broad maximum at about $30 \mathrm{eV}$ below the energy of the main peak. A possible candidate for the production of slower $\mathrm{H}^{+}$could be the reaction:

$$
\mathrm{H}_{3}^{+}+\mathrm{H}_{2} \rightarrow 2 \mathrm{H}_{2}+\mathrm{H}^{+}
$$

with estimated cross sections [38] of $10^{-16}-10^{-17} \mathrm{~cm}^{2}$ for the collision energies of the plasma sheath, but other inelastic and charge transfer processes are probably involved too. The narrow peak of $\mathrm{H}^{+}$ in the IED of figure 3 is due to $\mathrm{H}^{+}$thermal ions formed in the glow by reactions (2) and (3) and possibly by reaction (4) through electronic excitation into the repulsive part of the ${ }^{2} \Sigma_{\mathrm{g}}^{+}$state of $\mathrm{H}_{2}$, which correlates also with ground state $\mathrm{H}$ and $\mathrm{H}^{+}$. This latter process is possible for electron energies beyond $\sim 18 \mathrm{eV}$, but has a low probability due to an unfavourable Franck-Condon factor [42-43]. The $\mathrm{H}$ atoms involved in reactions (2) and (3) are produced in the discharge through 
different reactions [23], but they only recombine to give $\mathrm{H}_{2}$ at the reactor surfaces. A comparatively high steady-state concentration of hydrogen atoms (typically $\sim 10 \%$ ) is found for the conditions of the discharges shown in figure 3, which is consistent with a small wall recombination coefficient of $\mathrm{H}$ in stainless steel $[23,46]$. Note that the dominance of $\mathrm{H}_{2}$ over $\mathrm{H}$ as a precursor of $\mathrm{H}^{+}$can be compensated by the fact that the rate constant $\mathrm{k}_{4}$ is at least one order of magnitude smaller than $\mathrm{k}_{2}$ and $\mathrm{k}_{3}$ for electron temperatures up to $\mathrm{T}_{\mathrm{e}} \sim 7 \mathrm{eV}$.

Ion energy distributions have also been studied for discharges in mixtures of $\mathrm{H}_{2}$ and Ar. $\mathrm{Ar}+\mathrm{H}_{2}$ discharges are also frequently used for sputtering systems and as a source of atomic hydrogen [47]. Figure 5 displays the results for the main ions found in a plasma mixture of $\mathrm{H}_{2}+\mathrm{Ar}$ (7\%), at $2 \mathrm{~Pa}$. It can be seen that the concentration of the protonated ions $\mathrm{H}_{3}{ }^{+}$and $\mathrm{ArH}^{+}$exceeds by far those of $\mathrm{H}_{2}^{+}$and $\mathrm{Ar}^{+}$. The concentration of $\mathrm{Ar}^{++}$is also relatively high. $\mathrm{ArH}^{+}$is generated mostly by the barrier free reactions [39]:

$$
\begin{array}{ll}
\mathrm{Ar}+\mathrm{H}_{2}^{+} \rightarrow \mathrm{ArH}^{+}+\mathrm{H} & \mathrm{k}_{6}=2.10 \cdot 10^{-9} \mathrm{~cm}^{3} \mathrm{~s}^{-1} \\
\mathrm{Ar}^{+}+\mathrm{H}_{2} \rightarrow \mathrm{ArH}^{+}+\mathrm{H} & \mathrm{k}_{7}=2.10 \cdot 10^{-9} \mathrm{~cm}^{3} \mathrm{~s}^{-1} \\
\mathrm{Ar}+\mathrm{H}_{3}{ }^{+} \rightarrow \mathrm{ArH}^{+}+\mathrm{H}_{2} & \mathrm{k}_{8}=3.65 \cdot 10^{-10} \mathrm{~cm}^{3} \mathrm{~s}^{-1}
\end{array}
$$

On the other hand, $\mathrm{ArH}^{+}$recombines with $\mathrm{H}_{2}$ through the reaction [39]:

$$
\mathrm{ArH}^{+}+\mathrm{H}_{2} \rightarrow \mathrm{H}_{3}{ }^{+}+\mathrm{Ar} \quad \mathrm{k}_{9}=6.3 .10 \cdot 10^{-10} \mathrm{~cm}^{3} \mathrm{~s}^{-1}
$$

Whose rate coefficients are roughly independent of temperature. Note that $\mathrm{k}_{8}$ and $\mathrm{k}_{9}$, which correspond to reactions of $\mathrm{H}_{3}{ }^{+}$and $\mathrm{ArH}^{+}$with the prevailing neutral precursors $\left(\mathrm{H}_{2}\right.$ and $\left.\mathrm{Ar}\right)$, are considerably lower than $\mathrm{k}_{6}$ and $\mathrm{k}_{7}$, which involve $\mathrm{Ar}^{+}$and $\mathrm{H}_{2}{ }^{+}$as reactants. $\mathrm{H}_{3}{ }^{+}, \mathrm{ArH}^{+}$and $\mathrm{Ar}^{++}$have energy distributions (figure 5.a) very similar to that of $\mathrm{H}_{3}{ }^{+}$in pure $\mathrm{H}_{2}$ plasmas (figure 3), with a sharp peak and a weak tail at lower energies, indicating the low efficiency of collisions with the dominant species in the sheath. On the contrary, broad low energy wings, associated with efficient inelastic or charge transfer processes like those discussed in the previous paragraphs, can be observed in the $\mathrm{H}^{+}, \mathrm{H}_{2}^{+}$and $\mathrm{Ar}^{+}$distributions (figure 5.b). The origin of the high energy contribution to the IED of $\mathrm{H}^{+}$, analogous to that in figure 3.a, has been also discussed at length above.

Figures 6 and 7 show the IED for the main ions found in a $\mathrm{H}_{2}+\mathrm{O}_{2}(20 \%), 0.7 \mathrm{~Pa}$ discharge and in a $\mathrm{H}_{2}+\mathrm{N}_{2}(7 \%), 2 \mathrm{~Pa}$ discharge, respectively. Now, two different diatomic molecules are the plasma precursors in each case and, once more, $\mathrm{H}_{2}$ is the major species. The atoms generated in the electron impact dissociation of the precursors produce the stable molecules $\mathrm{H}_{2} \mathrm{O}$ and $\mathrm{NH}_{3}$, respectively, in heterogeneous wall reactions [48,49]. The upper panels of figures 6 and 7 display IED for the ions proceeding from protonation of the neutral species present in the plasmas; i.e., $\mathrm{H}_{3}{ }^{+}$, $\mathrm{H}_{3} \mathrm{O}^{+}$and $\mathrm{O}_{2} \mathrm{H}^{+}$in $\mathrm{H}_{2}+\mathrm{O}_{2}$ plasmas (figure 6.a) and $\mathrm{H}_{3}{ }^{+}, \mathrm{NH}_{4}{ }^{+}$and $\mathrm{N}_{2} \mathrm{H}^{+}$in $\mathrm{H}_{2}+\mathrm{N}_{2}$ plasmas (figure 
7.a). All of them have energy distributions quite similar to that of $\mathrm{H}_{3}{ }^{+}$in pure $\mathrm{H}_{2}$ discharges, with narrow peaks weakly affected by sheath collisions, indicative of their relatively high stability in these hydrogen dominated media. Note that $\mathrm{H}_{3}{ }^{+}, \mathrm{N}_{2} \mathrm{H}^{+}$and $\mathrm{H}_{3} \mathrm{O}^{+}$ions belong to the very reduced group of ions that have been observed till now in the interstellar medium or circumstellar shells [50]. $\mathrm{H}_{3} \mathrm{O}^{+}$and $\mathrm{NH}_{4}{ }^{+}$are the most abundant ions in their respective discharges and $\mathrm{H}_{3}{ }^{+}$and $\mathrm{N}_{2} \mathrm{H}^{+}$ are major ions too. $\mathrm{H}_{3}{ }^{+}$shows in all the cases the sharpest fall of the narrow peak at low energies. The middle panels of figures 6 and 7 show the ions formed directly from precursors and stable neutral molecules: $\mathrm{H}_{2}{ }^{+}, \mathrm{H}_{2} \mathrm{O}^{+}$and $\mathrm{O}_{2}{ }^{+}$in figure 6.b, and $\mathrm{H}_{2}{ }^{+}, \mathrm{NH}_{3}{ }^{+}$and $\mathrm{N}_{2}{ }^{+}$, as well as the $\mathrm{NH}_{2}{ }^{+}$ fragment of ammonia, in figure 7.b. They exhibit broad wings at low energies, which are found to have a marked dependence on pressure (not shown for simplicity) reminiscent of that already discussed for $\mathrm{Ar}^{+}$and $\mathrm{H}_{2}^{+}$. The lower panels of these figures show the ions whose energy distributions contain high energy tails extending appreciably (several eV) beyond the maximum. These ions are: $\mathrm{H}^{+}, \mathrm{O}^{+}, \mathrm{OH}^{+}$and $\mathrm{O}^{++}$in the $\mathrm{H}_{2}+\mathrm{O}_{2}$ discharge (figure 6.c) and $\mathrm{H}^{+}, \mathrm{N}^{+}, \mathrm{NH}^{+}$and $\mathrm{N}^{++}$ in the $\mathrm{H}_{2}+\mathrm{N}_{2}$ discharge (figure 7.c). Low energy wings are also found in the corresponding IED, except for $\mathrm{O}^{++}$and $\mathrm{N}^{++}$. For these doubly charged ions, present in very small concentrations, a possible low energy wing could be below the detection limit.

The production of fast $\mathrm{N}^{+}$and $\mathrm{O}^{+}$ions in electron impact processes has been also studied by different groups (see for instance [44] and references therein). In both cases, the predominant production mechanism is excitation to a bound electronic state of the molecular ion, followed by predissociation. The main predissociating states have been identified in electron beam experiments as $\mathrm{C}^{2} \Sigma_{\mathrm{u}}{ }^{+}$for $\mathrm{N}_{2}{ }^{+}$and $\mathrm{B}^{2} \Sigma_{\mathrm{g}}$ for $\mathrm{O}_{2}{ }^{+}$, but other states of the molecular ions are also implied [51-54]. The ion kinetic energy distributions of these experiments have one maximum close to zero eV and smaller maxima at kinetic energies lower than $5 \mathrm{eV}$, which is in accordance with the range of the high energy shoulders in the IED of $\mathrm{N}^{+}$and $\mathrm{O}^{+}$measured in this work (figures 6.c and 7.c). Although the global shape is preserved, the finer structure appearing in the kinetic energy distribution of the beam experiments is averaged off in our discharges by the spread of collision energies and reactants' orientations.

High energy tails are also observed in the IED of $\mathrm{NH}^{+}$and $\mathrm{OH}^{+}$. These ions are formed from their respective parent molecules $\left(\mathrm{NH}_{3}\right.$ and $\left.\mathrm{H}_{2} \mathrm{O}\right)$ through electron impact. Although the detailed mechanisms of the dissociative ionization of water and ammonia are not so well known as those of the diatomic molecules discussed previously, it seems that $\mathrm{NH}^{+}$and $\mathrm{OH}^{+}$are formed with little kinetic energy (see [55-57] and references therein). Concurrent processes leading to $\mathrm{OH}^{+}$and $\mathrm{NH}^{+}$ would be the ion molecule reactions [39]

$$
\mathrm{O}^{+}+\mathrm{H}_{2} \rightarrow \mathrm{OH}^{+}+\mathrm{H} \quad \mathrm{k}_{10}=1.62 \times 10^{-9} \mathrm{~cm}^{3} \mathrm{~s}^{-1}
$$




$$
\mathrm{N}^{+}+\mathrm{H}_{2} \rightarrow \mathrm{NH}^{+}+\mathrm{H} \quad \mathrm{k}_{11}=5.0 \times 10^{-10} \mathrm{~cm}^{3} \mathrm{~s}^{-1}
$$

with large rate coefficients. In these reactions, the comparatively heavy atomic ions formed with high kinetic energy through dissociative ionization, behave as "spectators" [58] (i.e. preserve essentially their initial momentum during the collision) and pick the light $\mathrm{H}$ atom without significant velocity change, giving rise to fast $\mathrm{OH}^{+}$and $\mathrm{NH}^{+}$ions. These fast molecular ions could account, at least partly, for the observed high energy tails of $\mathrm{OH}^{+}$and $\mathrm{NH}^{+}$. Note that in the $\mathrm{H}_{2}+\mathrm{Ar}$ discharge, the IED of the $\mathrm{ArH}^{+}$ion, which is not formed in dissociative ionization processes or in collisions with fast atomic ions, but rather through reactions (6-8), has no high energy shoulder (figure 5.a). The different distributions of doubly ionized atoms in figures 2 and 5-7, with the IED of $\mathrm{Ar}^{++}$spreading to lower energies and those of $\mathrm{O}^{++}$and $\mathrm{N}^{++}$displaying only high energy shoulders, is also worth observing and suggests the likely formation of $\mathrm{O}^{++}$and $\mathrm{N}^{++}$by some dissociative ionization process from the corresponding precursor molecules. Formation and charge transfer collision processes of doubled charged species like $\mathrm{Ar}^{++}$and $\mathrm{N}^{++}$ions have been published in the literature [59-61]. Air discharges under similar conditions have also been studied in our laboratory $[22,62]$ and the corresponding energy distributions of oxygenic and nitrogenic ions: $\mathrm{N}^{+}$, $\mathrm{N}^{++}, \mathrm{N}_{2}{ }^{+}, \mathrm{O}^{+}, \mathrm{O}^{++}, \mathrm{O}_{2}^{+}$(not shown for brevity) are very similar to those shown in figures 6 and 7.

As discussed in the previous paragraphs, the identification of the physico-chemical processes determining the distinct features in the IED is in many cases not possible; in spite of it, the specificity of the IED for the different ions (or at least ion groups) can be of great help for the discrimination of species with the same mass/charge $(\mathrm{m} / \mathrm{q})$ ratio but different chemical composition. We will illustrate this point with examples from discharges in mixtures of $\mathrm{H}_{2}$ with small amounts (5\%) of $\mathrm{CH}_{4}$ and/or $\mathrm{N}_{2}$ at $2 \mathrm{~Pa}$. Discharges of $\mathrm{H}_{2}+\mathrm{CH}_{4}$ are frequently used in plasma-enhanced chemical vapour deposition of diamond-like and amorphous hydrogenated carbon (a-C:H) films $[63,64]$. In these plasmas, hydrogenic ions contribute to the formation of $\mathrm{C}_{x} \mathrm{H}_{y}{ }^{+}$species, which can play an important role in film growth [65]. $\mathrm{N}_{2}$ was introduced in hydrocarbon plasmas in an attempt to synthesize crystalline $\beta-\mathrm{C}_{3} \mathrm{~N}_{4}$, a material with predicted properties superior to those of diamond [66], but these studies showed that incorporation of nitrogen to the growing film is difficult; and furthermore, its presence can even hamper film formation [67]. The inhibition of a-C:H film growth by $\mathrm{N}_{2}$ has turned out to be of interest for nuclear fusion reactors in order to avoid the formation of carbon deposits rich in radioactive tritium in parts of the device not directly exposed to the hot plasma [15,68-69].

An overall picture of the chemistry underlying the ion distributions in the $\mathrm{H}_{2}+\mathrm{CH}_{4}+\mathrm{N}_{2}$ discharges considered was given in [24]. In these plasmas, carbon and nitrogen containing ions contribute often to the same mass spectral peak. In particular, $\mathrm{CH}_{2}{ }^{+}$and $\mathrm{N}^{+}$ions coincide at $m / q=$ 
14, whereas $\mathrm{CH}_{3}{ }^{+}$and $\mathrm{NH}^{+}$coincide at $m / q=15$. The same situation occurs for some heavier ions like $\mathrm{CH}_{5}{ }^{+}$vs. $\mathrm{NH}_{3}{ }^{+}, \mathrm{C}_{2} \mathrm{H}_{5}{ }^{+}$vs. $\mathrm{N}_{2} \mathrm{H}^{+}$, and so on. In figures 8 and 9 , the separated IED at $m / q=14$ (figure 8) and $m / q=15$ (figure 9) for the three plasma precursor mixtures mentioned above are displayed. The results from the binary mixtures $\mathrm{H}_{2}+\mathrm{CH}_{4}$ and $\mathrm{H}_{2}+\mathrm{N}_{2}$ are shown in the upper panels and those from the ternary mixture $\mathrm{H}_{2}+\mathrm{CH}_{4}+\mathrm{N}_{2}$, in the lower ones. The energy scales have been conveniently shifted for the different discharges, so that the $E_{m}$ values coincide at the same position. Different IED shapes are observed for both masses, 14 and 15 a.m.u, depending of the precursor mixture. So, in the $\mathrm{H}_{2}+\mathrm{CH}_{4}$ discharge, low energy wings are observed for the two masses, corresponding to $\mathrm{CH}_{2}{ }^{+}$and $\mathrm{CH}_{3}{ }^{+}$, whereas these wings do not appear in the $\mathrm{H}_{2}+\mathrm{N}_{2}$ discharge (Figures 8.a, 9.a), where the detected ions are $\mathrm{N}^{+}$and $\mathrm{NH}^{+}$. The sums of the independent IED distributions of $\mathrm{H}_{2}+\mathrm{CH}_{4}$ and $\mathrm{H}_{2}+\mathrm{N}_{2}$ plasmas for $m / q=14$ and 15 are also shown in figures $8 . b$ and 9.b, respectively. These sums are found to be coincident with the IED distributions corresponding to the $\mathrm{H}_{2}+\mathrm{CH}_{4}+\mathrm{N}_{2}$ discharges. From the comparison of these data it is possible to deduce that in the $\mathrm{H}_{2}+\mathrm{CH}_{4}+\mathrm{N}_{2}$ plasma, $\mathrm{CH}_{2}^{+}$and $\mathrm{N}^{+}$ions $(\mathrm{m} / \mathrm{q}=14)$ are present in comparable amounts $(\sim 50 \%)$ (figure 8), whereas the contribution of $\mathrm{NH}^{+}$to $m / q=15$ is roughly $5 \%$, and $\mathrm{CH}_{3}{ }^{+}$turns out to be much more abundant (figure 9). These findings provide an unambiguous verification of our previous estimate based on the comparison of the relative integrated ion signals [24]. The likely mechanisms for the production of $\mathrm{N}^{+}$and $\mathrm{NH}^{+}$ions in $\mathrm{H}_{2}+\mathrm{N}_{2}$ plasmas have been discussed above. The complexity of the chemistry in hydrocarbon plasmas is much higher but still some global considerations can be made about the results of figures 8 and 9 . The peaks centred at about $E_{m}$ correspond to ions coming directly from the glow region, whereas the low energy contributions to the global IED are due to inelastic collisions or ion molecule reactions in the sheath. It is interesting to observe that the ratio between the $\mathrm{E}_{\mathrm{m}}$ peak and the lower energy contribution is much smaller in the case of $m / q=14$ than in that of $m / q=15$, which suggests that collisions of $\mathrm{CH}_{2}{ }^{+}$with $\mathrm{H}_{2}$ (the dominant species) are much more efficient than those of $\mathrm{CH}_{3}{ }^{+}$over the collision energy range pertinent to the sheath (approximately $0-350 \mathrm{eV}$ ).

\section{Summary and conclusions}

Energy distributions of ions reaching the cathode in low pressure DC plasmas have been measured. Different gases and gas mixtures including $\mathrm{Ar}, \mathrm{H}_{2}, \mathrm{~N}_{2}, \mathrm{O}_{2}$ and $\mathrm{CH}_{4}$ were used as plasma precursors. The analysis of the energy distributions has provided interesting clues about physicochemical processes within the glow region or in the plasma sheath. For the lowest pressures investigated $(<2 \mathrm{~Pa})$, most ions reach the cathode with an energy gain close to that corresponding to the anode- 
cathode potential difference, and contributions at higher energies reflect the occurrence of dissociative ionization processes within the glow. The evolution of these high energy contributions with discharge conditions, and especially with gas pressure, is sensitive to the electron temperature in the plasma. With increasing gas pressure, the energy distributions can be significantly distorted by collisions in the sheath. An appraisal of the extent and nature of sheath collisions is in general needed to relate the measured ion signals with the actual ion densities in the plasma. In plasmas dominated by $\mathrm{H}_{2}$ or Ar, symmetric charge exchange can explain the distortions observed in the $\mathrm{H}_{2}{ }^{+}$ and $\mathrm{Ar}^{+}$distributions for pressures of several $\mathrm{Pa}$.

Protonated ions like $\mathrm{H}_{3}{ }^{+}, \mathrm{ArH}^{+}, \mathrm{N}_{2} \mathrm{H}^{+}, \mathrm{H}_{3} \mathrm{O}^{+}$and so on show in general a high stability in $\mathrm{H}_{2}$ media, evinced by the narrow peaks, weakly affected by collisions, and by their high concentration as compared with the non protonated ions.

A comparison of the measured distributions with literature results of electron beam experiments has allowed the identification of the main dissociative ionization mechanisms for the diatomic molecules $\left(\mathrm{H}_{2}, \mathrm{O}_{2}, \mathrm{~N}_{2}\right)$ in the plasmas. Other processes determining the various types of energy distributions found in the experiments could only be hinted at, but even without a detailed explanation of the observed distribution shapes, the specificity of the distributions for different ions allowed the discrimination between ionic species with the same mass to charge ratio and different composition in plasmas of $\mathrm{H}_{2}$ with $\mathrm{N}_{2}$ and $\mathrm{CH}_{4}$.

The analysis of ion-energy distribution reported in this work can be extended to plasmas of different type or composition where it is expected to provide valuable insight into the underlying ion chemistry.

\section{Aknowledgements}

The technical advice of J M Castillo, M A Moreno and J Rodriguez has been most valuable for the achievement of the present results. This work has been funded by the DGI (MEC) of Spain under grants ENE 2006-14577-C04-03/FTN and FIS 2007-61686.

\section{$\underline{\text { References }}$}

[1] Röpcke J, Lombardi G, Rousseau A and Davies P B 2006 Plasma Sources Sci. Technol. 15 S148-68

[2] Stancu G D, Pipa AV, Lombardi G, Davies P B, Gicquel A, Lavrov P B and Röpcke J 2005 Contrib. Plasma Phys. 45, 358-68

[3] Tanarro I, Sanz M M, Bermejo D, Domingo C and Santos J 1994 J. Chem. Phys.100, 238-46

[4] Tanarro I, Sanz M M, Domingo C, Bermejo D, Santos J and Domenech J L 1994 J. Phys. Chem.

98, 5862-6 
[5] de los Arcos T, Domingo C, Herrero V J, Sanz M M, Schulz A and Tanarro I 1998 J. Phys. Chem. A 102, 6282-91

[6] Tabares FL, Tafalla D, Tanarro I, Herrero V J and Islyaikin A M 2004 Vacuum 73, 161-7

[7] Mutsukura N 2001 Plasma Chem. Plasma Process. 21265

[8] Sugai H, Kojima H, Ishida A and Toyoda H 1990 Appl. Phys. Lett. 56, 2616-8

[9] Sanz M M, Abad L, Herrero V J and Tanarro I 1992 J.Appl.Phys.71, 5372-6

[10] Ferreira J A and Tabares F L 2007 J. Vac. Sci. Tech. A 25, 246-51

[11] Kang H D, Preuss R, Schwarz-Selinger T and Dose V 2002 Journal of Mass Spectrometry 37, 748-54

[12] Singh H, Coburn J W and Graves D B 2000 J. Vac. Sci. Technol. A 18, 299-305

[13] Tanarro I 2007 J. Phys. D: Appl. Phys. 40, 2994-5

[14] Hopf C, Jacob W and von Keudell A 2005 J. Appl. Phys. 97, 094904.

[15] Schlüter M, Hopf C and Jacob W 2008 New J. Physics 10, 053037.

[16] Plagernann A, Ellmer K and Wiesemann K 2007 J. Vac. Sci. Tech. A 25, 1341-50

[17] Ellmer K, Wendt R and Wiesemann K 2003 Int. J. Mass Spectr. 223, 679-93.

[18] Zeuner M, Neumann H and Meichsner J 1997 J. Appl. Phys. 81, 2985-94.

[19] Franke E, Neumann H, Zeuner M, et al. 1997 Surf. Coating Tech. 97, 90-6

[20] Snijkers R J M M, van Sambeek M J M, Hoppenbrouwers M B, et al. 1996 J. Appl. Phys. 79, 8982-92

[21] Herrero V J, Islyaikin A M and Tanarro I 2008 J. Mass Spectr. 43 [on line in advance of print DOI: $10.1002 /$ jms. 1388

[22] Castillo M, Méndez I, Islyaikin A M, Herrero V J and Tanarro I 2005 J. Phys. Chem.A, 109, 6255-63

[23] Méndez I, Gordillo-Vázquez F J, Herrero V J and Tanarro I 2006 J. Phys. Chem. A 110, 60606

[24] Tanarro I, Herrero V J, Islyaikin A M, Méndez I, Tabarés F L and Tafalla D 2007 J. Phys. Chem. A, 111, 9003-12

[25] Baguer N, Bogaerts A and Gijbels R 2003 J. Appl. Phys. 94, 2212-22

[26] de los Arcos T, Castillo M, Domingo C, Herrero V J, Sanz M M and Tanarro I, 2000 J. Phys. Chem. A 104, 8183-93

[27] Sar-el HZ 1967 Rev. Sci. Instrum. 38, 1210-6

[28] Davis W D and Vanderslice T A 1963 Phys. Rev. 131, 219-28

[29] Seebock RJ 1999 Surf. Coat. Technol. 116, 564-7

[30] Budtz-Jorgensen C V, Bottiger J and Kringhoj P 2000 Vacuum 56, 9-13 
[31] Copeland F B M and Crothers D S F 1997 Atomic Data and Nuclear Data Tables 65, 273-88

[32] Pullins S H, Dressler R A, Torrents R and Gerlich D 2000 Zeit. Phys. Chem. 214, 1279-97

[33] Neynaber R H and Tang S Y 1982 Chem. Phys. Lett. 92, 556-9.

[34] Smith D, Adams N G, Alge A, Villinger H and Lindinger W 1980 J. Phys. B: Atom. Mol. Phys. 13, 2787-99.

[35] Kersten H, Deutsch H, Steffen H, Kroesen G M W and Hippler R 2001 Vacuum 63, 385-431

[36] McCall B J, Oka t 2000 Science 287 1941-2

[37] Jacob W, Hopf C, Meier M and Schwarz-Selinger T 2005 Nuclear fusion research understanding plasma-surface interactions (Springer Series in Chemical Physics vol.78) pp 249-85 [38] Phelps A V 1990 J. Phys. Chem. Ref. Data 19, 653-75

[39] Anicich VG 2003 J.P.L. Publication 03-19 NASA

[40] Gentry RW, McClure DJ and Douglass CH 1975 Rev. Sci. Instrum. 46, 367-75

[41] Hollmann E M and Pigarov A Y 2002 Phys. Plasmas 9, 4330-9

[42] Dunn G H and Kieffer L J 1963 Phys. Rev. 132, 2109-17

[43] Köllman K 1975 Int. J. Mass Spectrom. Ion. Phys. 17, 261-285

[44] Van Zyl B and Stephen T M 1994 Phys. Rev. A 50, 3164-73

[45] Van Brunt Jr 1977 Phys. Rev. A 16, 1309-11.

[46] Tserepi A D and Miller T A 1994 J. Appl. Phys 75, 7231-6

[47] Thomas L, Jauberteau J L, Jauberteau I, Aubreton J and Catherinot A 1997 Plasma Chem. Plasma Processing 17, 193-206

[48] van Helden J H, Wagemans W, Yagci G, Zijlmans R A B, Schram D C, Engeln R, Lombardi G, Stancu G D and Ropcke J 2007 J. Appl. Phys. 101, 043305

[49] Zijlmans RAB, Ph.D. Thesis, "Molecule conversion in recombining plasmas - the role of radical-surface interactions" The Netherlands, 2008.

[50] http://www.ph1.uni-koeln.de/vorhersagen/

[51] Locht R and Schopman J 1974 Int. J. Mass Spectrom. Ion Phys. 15, 361-378.

[52] Locht R, Schopman J, Wankenne H and Momigny J 1975 Chem. Phys. 7, 393-404.

[53] Van Brunt R J, LawrencE G M, Kieffer L J and Slater J M 1975 J. Chem. Phys. 61, 2032-7

[54] Van Brunt R J and Kieffer L J 1975 J. Chem. Phys. 63, 3216-3221.

[55] Tan K T, Brion C E, Van der Leeuw Ph E and Van der Wiel M J 1978 Chem. Phys. 29, 299309.

[56] Rejoub R, Lindsay B G and Stebbings R F 2001 J. Chem. Phys. 155, 5053-8

[57] Frémont F, Leclercq, Hajaji A, Naja A, Lemennais P, Boulbain S, Broquin V and Chesnel J-Y 2005 Phys Rev A 72, 042702-1-4. 
[58] Levine R D, Bernstein R B 1987 Molecular reaction dynamics and chemical reactivity. Oxford University Press: Oxford.

[59] Franceschi P, Ascenzi D and Tosi P 2007 J. Chem. Phys. 126, 134310

[60] P. Franceschi et al. 2008 Int. J. Mass Spectrom. doi:10.1016/j.ijms.2008.07.020

[61] Church D A and Holzscheiter H M 1980 Chem.Phys.Lett.76, 109-12

[62] Castillo M, Herrero V J, Méndez I, Tanarro I 2004 Plasma Sources Sci. Tech. 13, 343-350

[63] Jacob W. 1998 Thin Solid Films, 326, 1.

[64] Gordillo-Vázquez F J, Herrero V J and Tanarro I 2007 Chem. Vap. Depossition 13 267-79.

[65] Bauer M, Schwarz-Selinger T, Jacob W and von Keudell A 2005 J. Appl. Phys 98073302

[66] Liu A Y, Cohen M L 1989 Science 245, 841.

[67] Tabarés F L, Tafalla D, Tanarro I, Herrero V J, Islyaikin A and Maffiotte C 2002 Plasma Phys. Control. Fusion 44, L37-42

[68] Tabarés F L,Tafalla D, Rohde V, Stamp M, Mathews G, Esser G, Philipps V, Doerner R and Baldwin M 2005 J. Nucl. Mater.337-339, 867-71

[69] Schwarz-Selinger T, Hopf C, Sun C and Jacob W 2007 J. Nucl. Mater. 363, 174-8.

\section{Figure captions}

Figure 1 Experimental set up showing the hollow cathode discharge reactor geometry and the techniques used for the diagnostic of charged species. The negative glow, which constitutes the plasma region, characterized by a nearly zero electric field, is indicated, as well as the surrounding zone of cathode sheath, with remarkably lower electron density and a large potential fall.

Figure 2 Energy distributions of ions reaching the cathode in Ar dc discharges at $0.7 \mathrm{~Pa}$ (a) and 4 $\mathrm{Pa}(\mathrm{b})$. The distribution is represented in terms of the reduced energy $E=E_{k i n} / q$ where $E_{k i n}$ is the kinetic energy and $q$ the ion charge (see text). In (b) the solid curve through the experimental trace of $\mathrm{Ar}^{+}$corresponds to a fit of the data with the model of Davis and Vanderslice [28]. The $S / \lambda$ quotient is the ratio of sheath width to mean free path estimated from this fit (see text).

Figure 3 Energy distributions of ions reaching the cathode in $\mathrm{H}_{2}$ dc discharges. (a) $\mathrm{P}=2 \mathrm{~Pa}$, (b) $\mathrm{P}=20 \mathrm{~Pa}$. In (b) the solid curve through the $\mathrm{H}_{2}{ }^{+}$corresponds to a fit of the data with the model of Davis and Vanderslice [28]. The $S / \lambda$ quotient is the ratio of sheath width to mean free path estimated from this fit (see text). 
Figure 4. Left panel: scheme of the main energy levels involved in the electron impact dissociative ionization of $\mathrm{H}_{2}$ (adapted from [42]. Right panel: energy distributions of the $\mathrm{H}^{+}$ions produced. The solid line corresponds to the results of Fig 3a. The energy origin has been placed at the maximum of the narrow peak (i.e. $\approx$ anode-cathode potential difference). The symbols correspond to the electron beam measurements of van Brunt [45] for electron energy of $75 \mathrm{eV}$ and scattering angle of $23^{\circ}$

Figure 5 Energy distributions of ions reaching the cathode in a dc discharge of $\mathrm{H}_{2}+\mathrm{Ar}(7 \%)$ at a total pressure of $2 \mathrm{~Pa}$.

Figure 6 Energy distributions of ions reaching the cathode in a dc discharge of $\mathrm{H}_{2}+\mathrm{O}_{2}(20 \%)$ at a total pressure of $2 \mathrm{~Pa}$.

Figure 7 Energy distributions of ions reaching the cathode in a de discharge of $\mathrm{H}_{2}+\mathrm{N}_{2}(7 \%)$ at a total pressure of $2 \mathrm{~Pa}$.

Figure 8 Energy distributions of $\mathrm{CH}_{2}{ }^{+}$and $\mathrm{N}^{+}$ions $(\mathrm{m} / \mathrm{q}=14)$ reaching the cathode in dc discharges of different mixtures at a total pressure of $2 \mathrm{~Pa}$. Upper panel: discharges in binary mixtures $\left(\mathrm{H}_{2}+5 \%\right.$ $\mathrm{CH}_{4}$ and $\left.\mathrm{H}_{2}+5 \% \mathrm{~N}_{2}\right)$. Lower panel: discharge in a ternary mixture $\left(\mathrm{H}_{2}+5 \% \mathrm{CH}_{4}+5 \% \mathrm{~N}_{2}\right)$ and sum of the signals corresponding to the binary mixtures of the upper panel.

Figure 9 Same as figure 8, but for the ions $\mathrm{CH}_{3}{ }^{+}$and $\mathrm{NH}^{+}(\mathrm{m} / \mathrm{q}=15)$. 


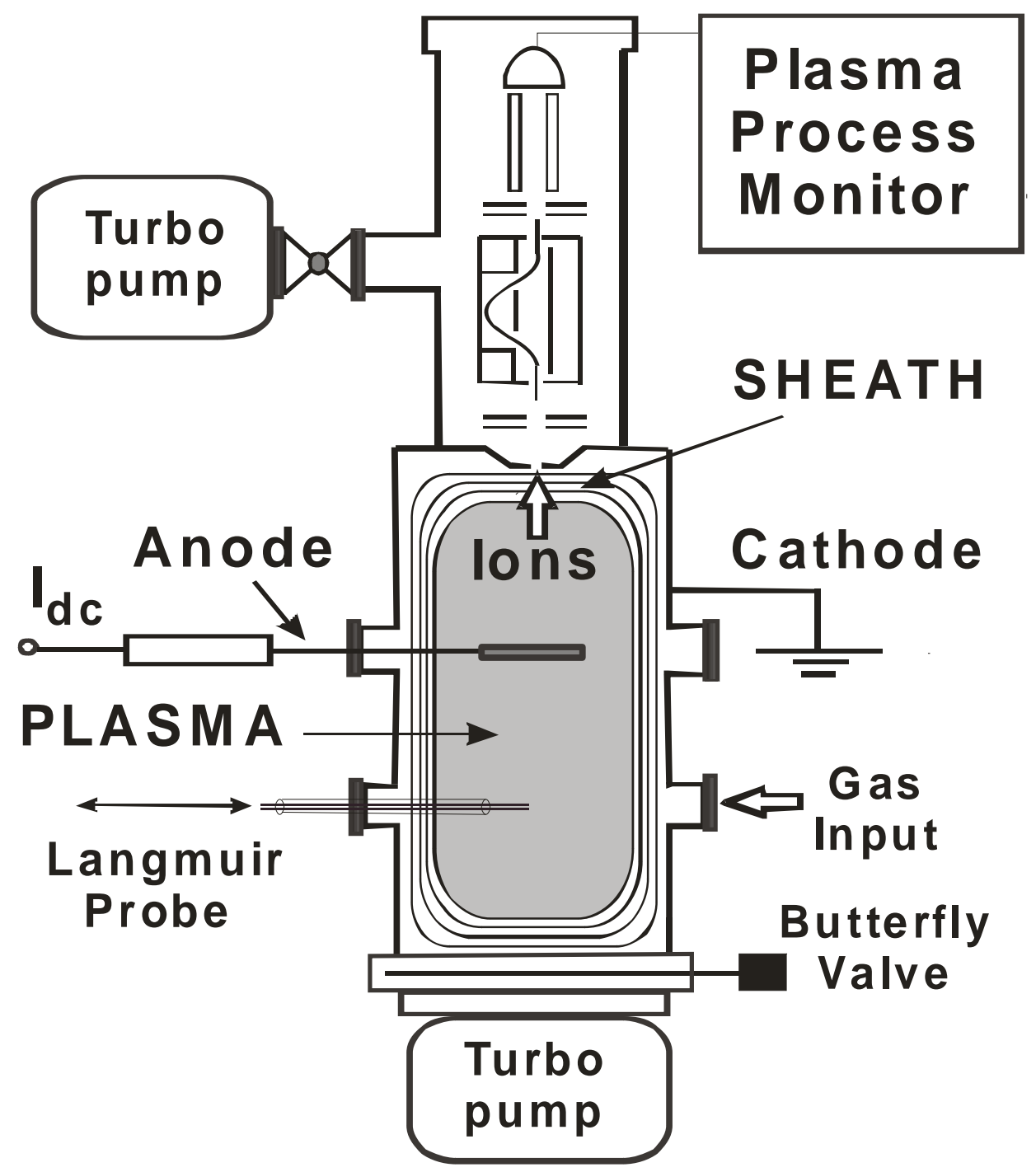

Figure 1 


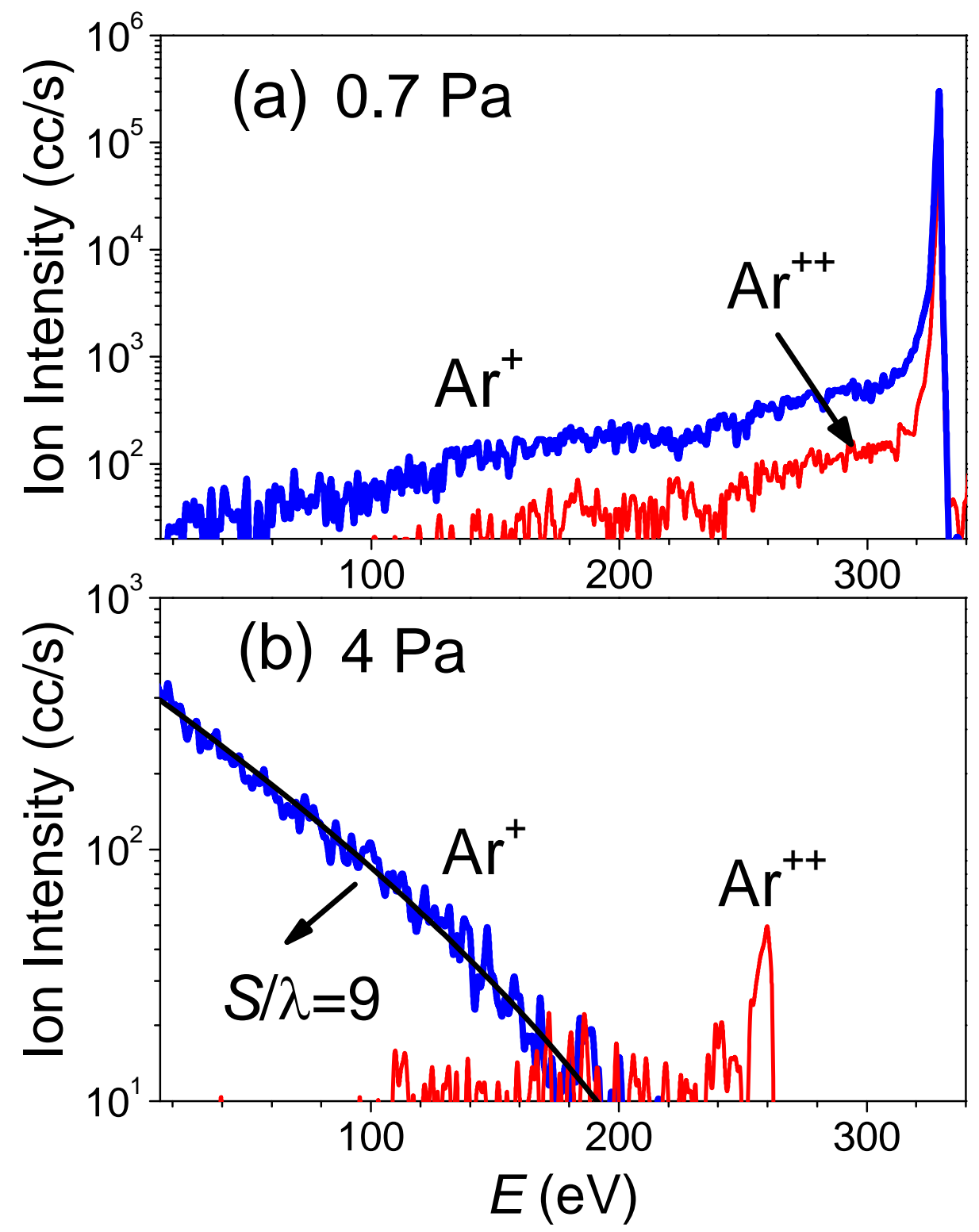

Figure 2 


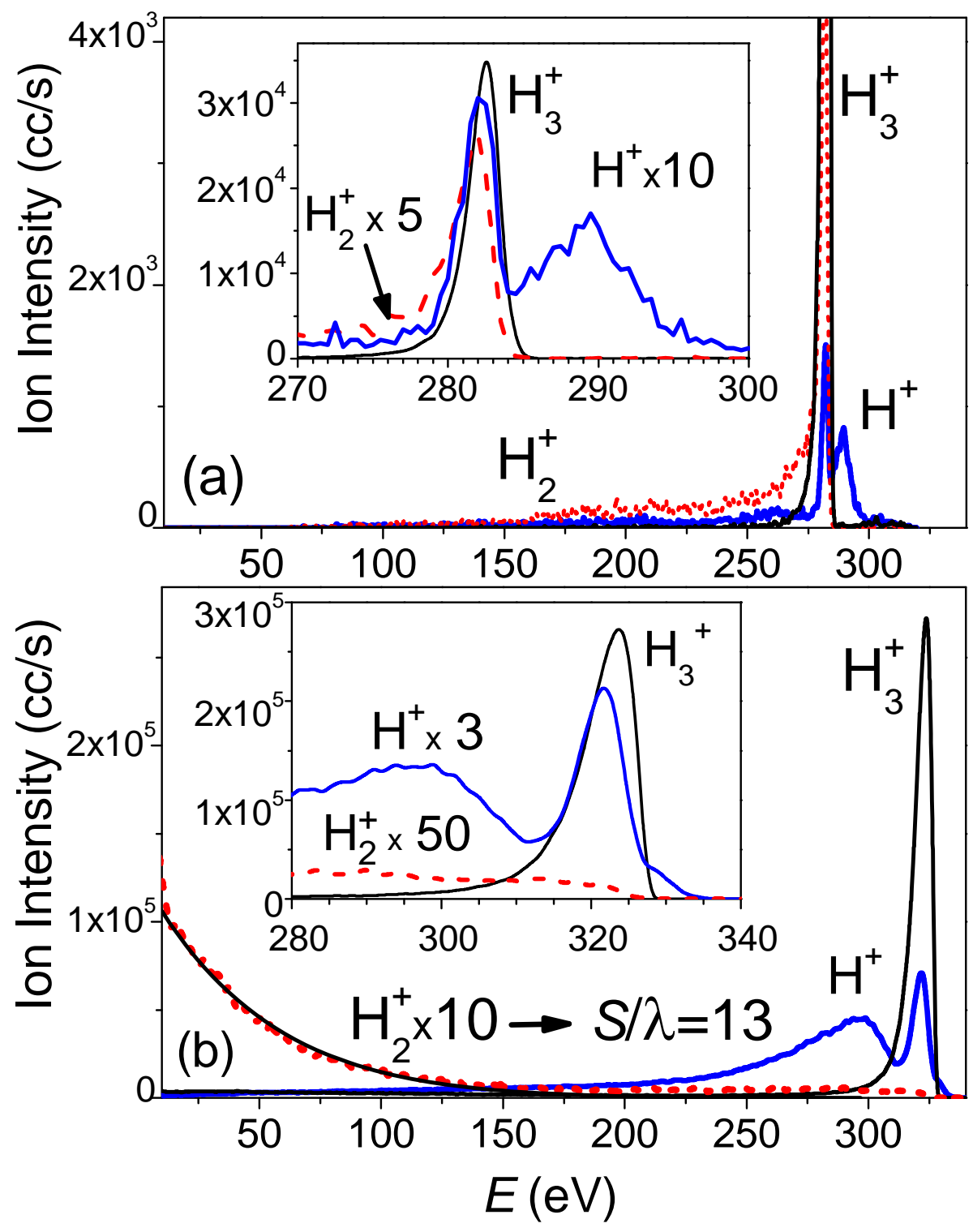

Figure 3 


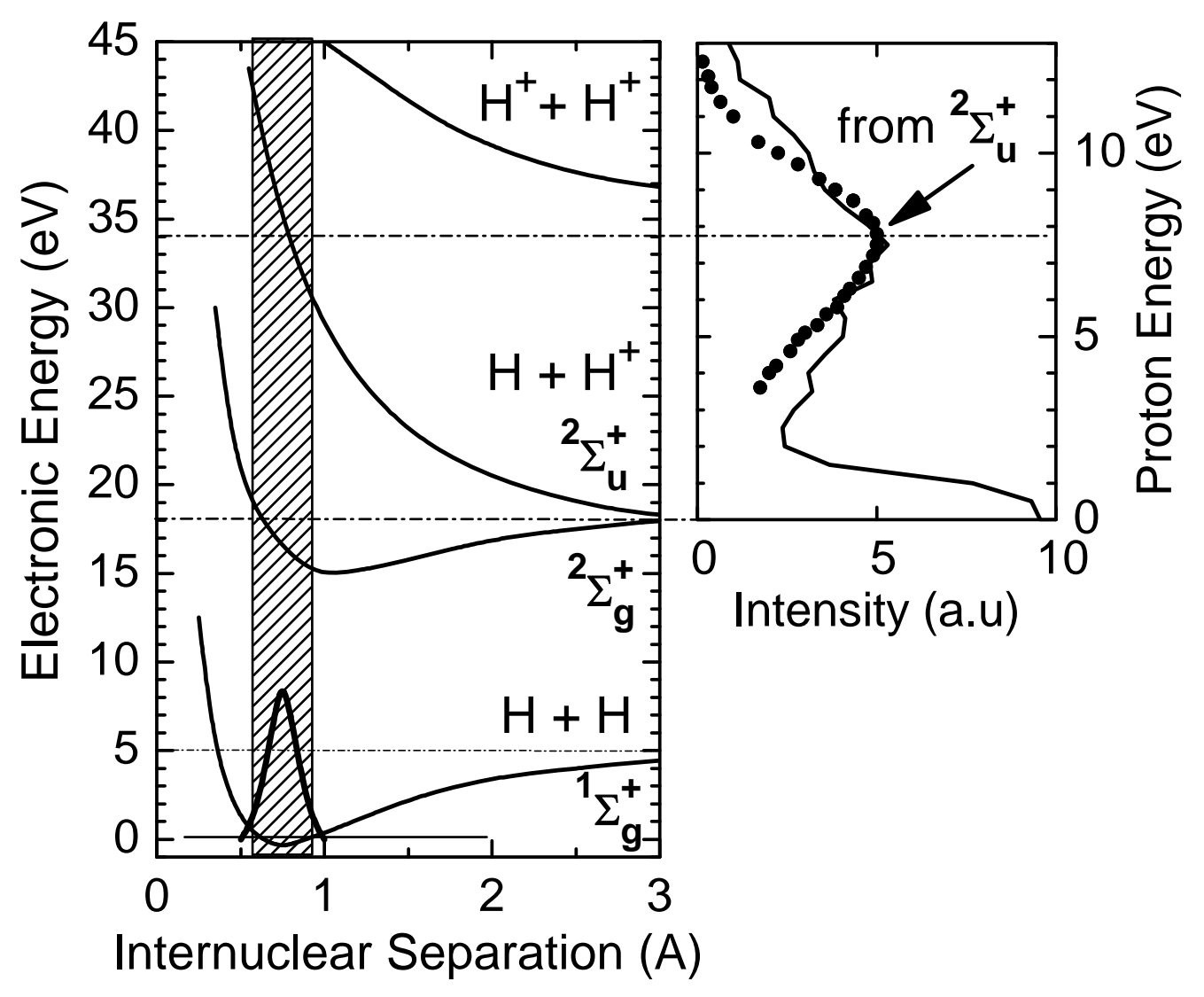

Figure 4 


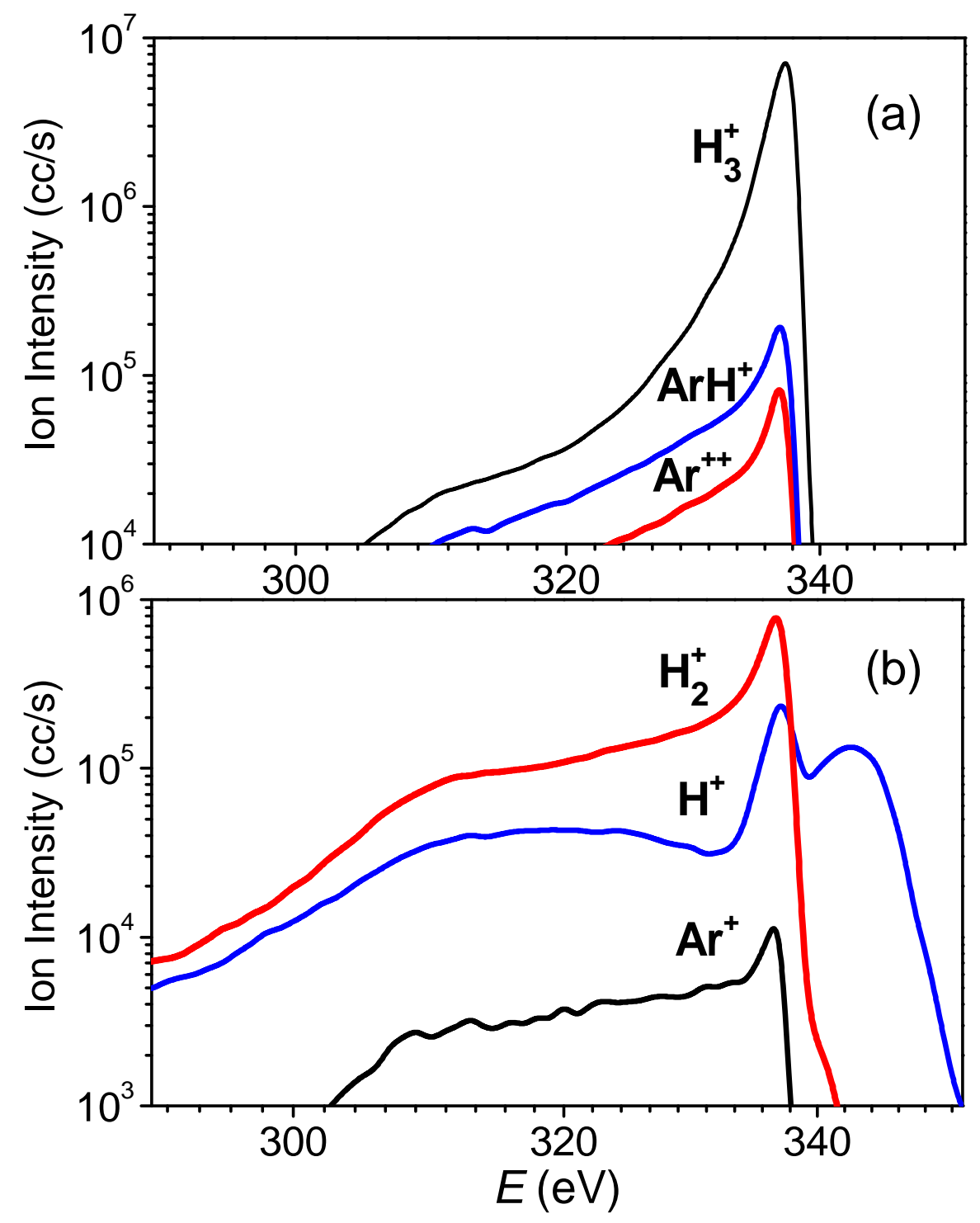

Figure 5 

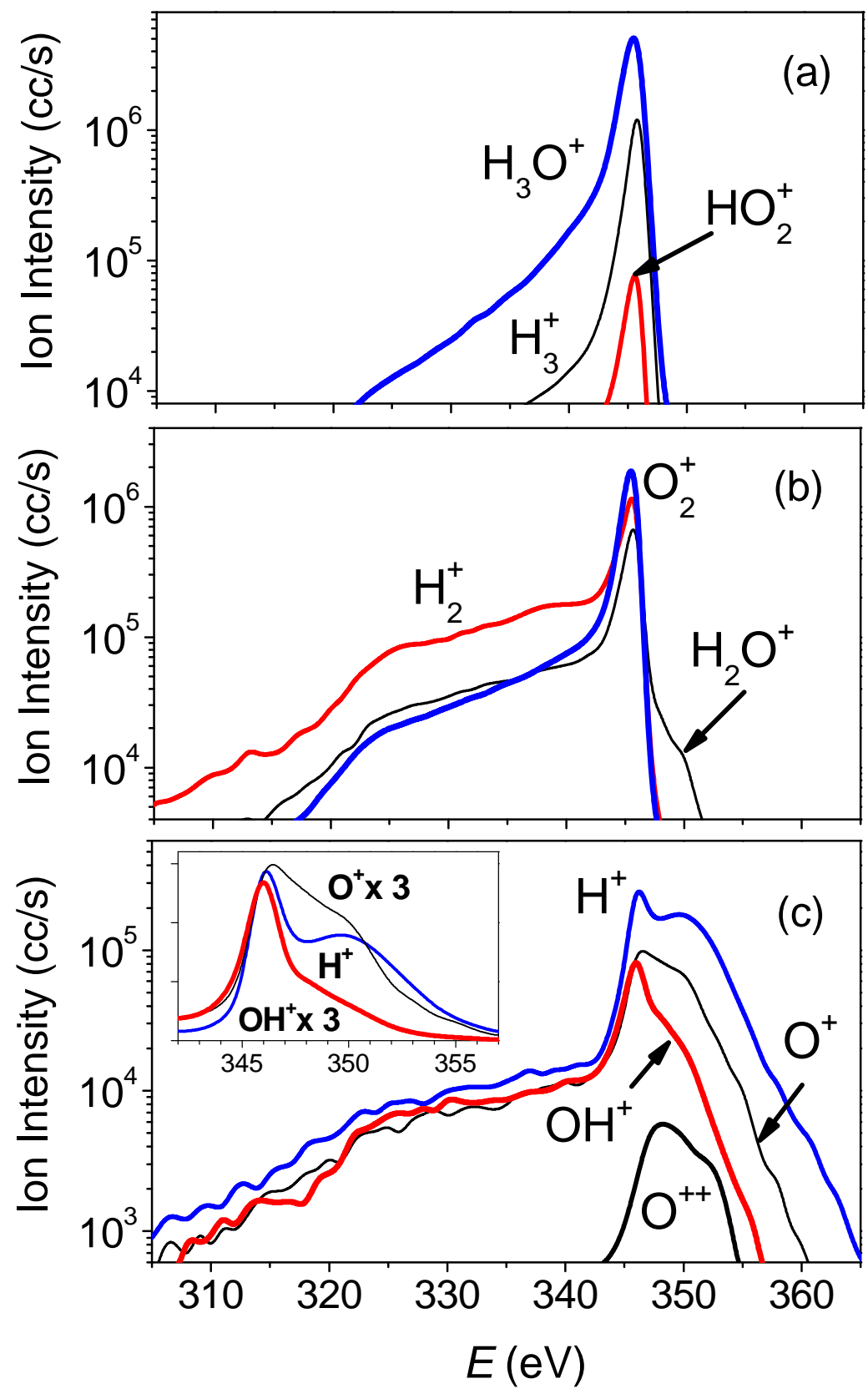

Figure 6 

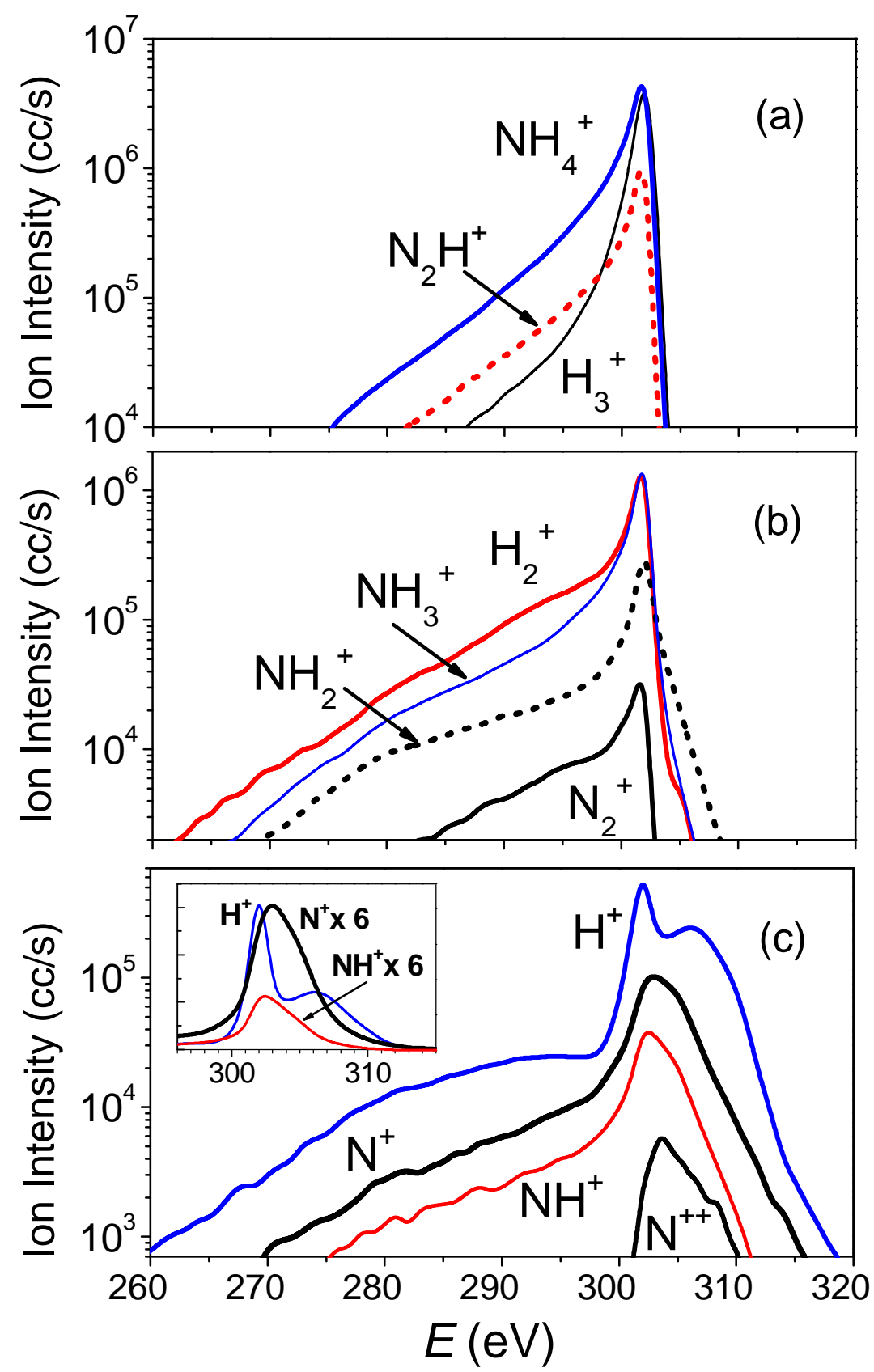

Figure 7 


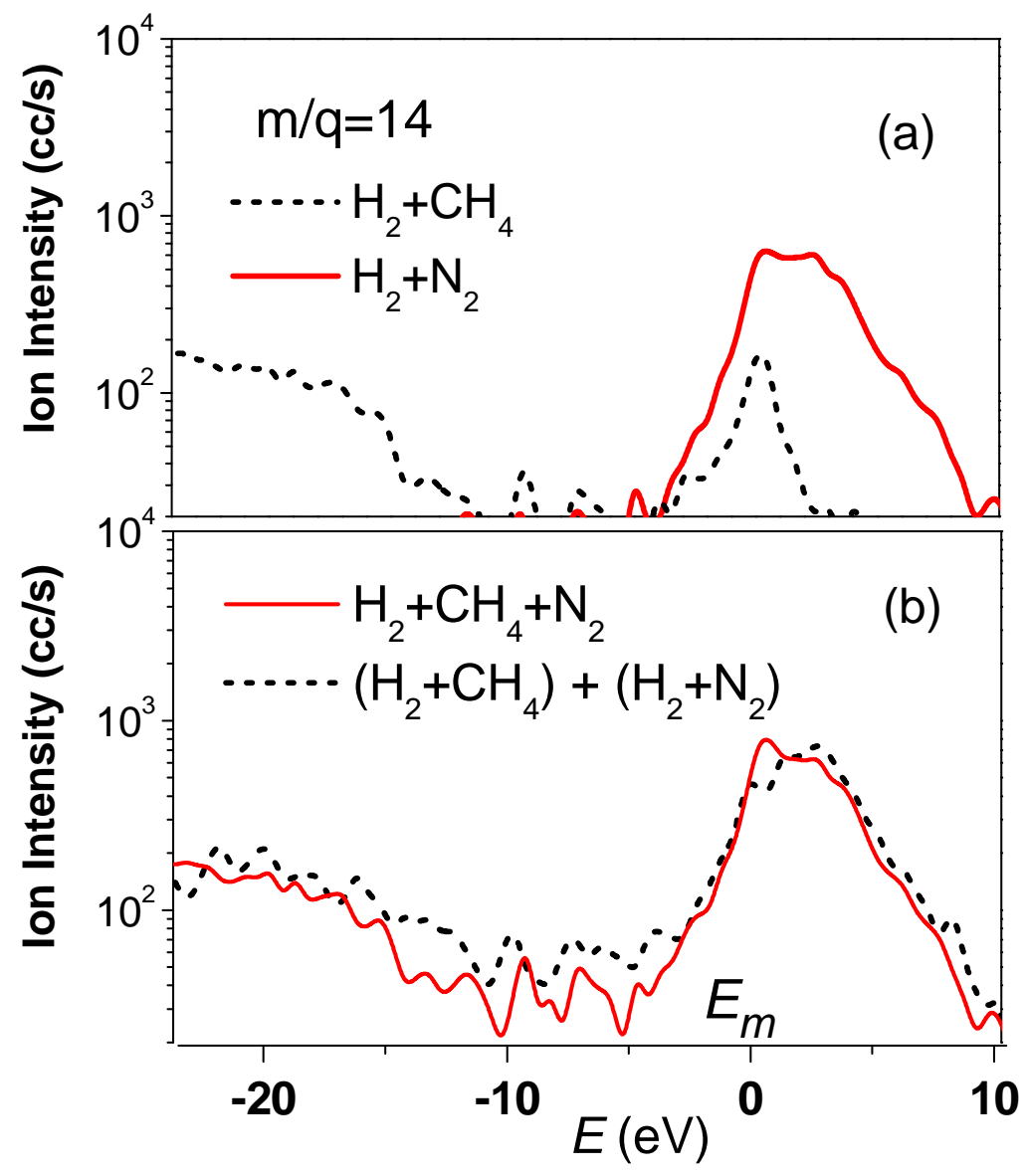

Figure 8 


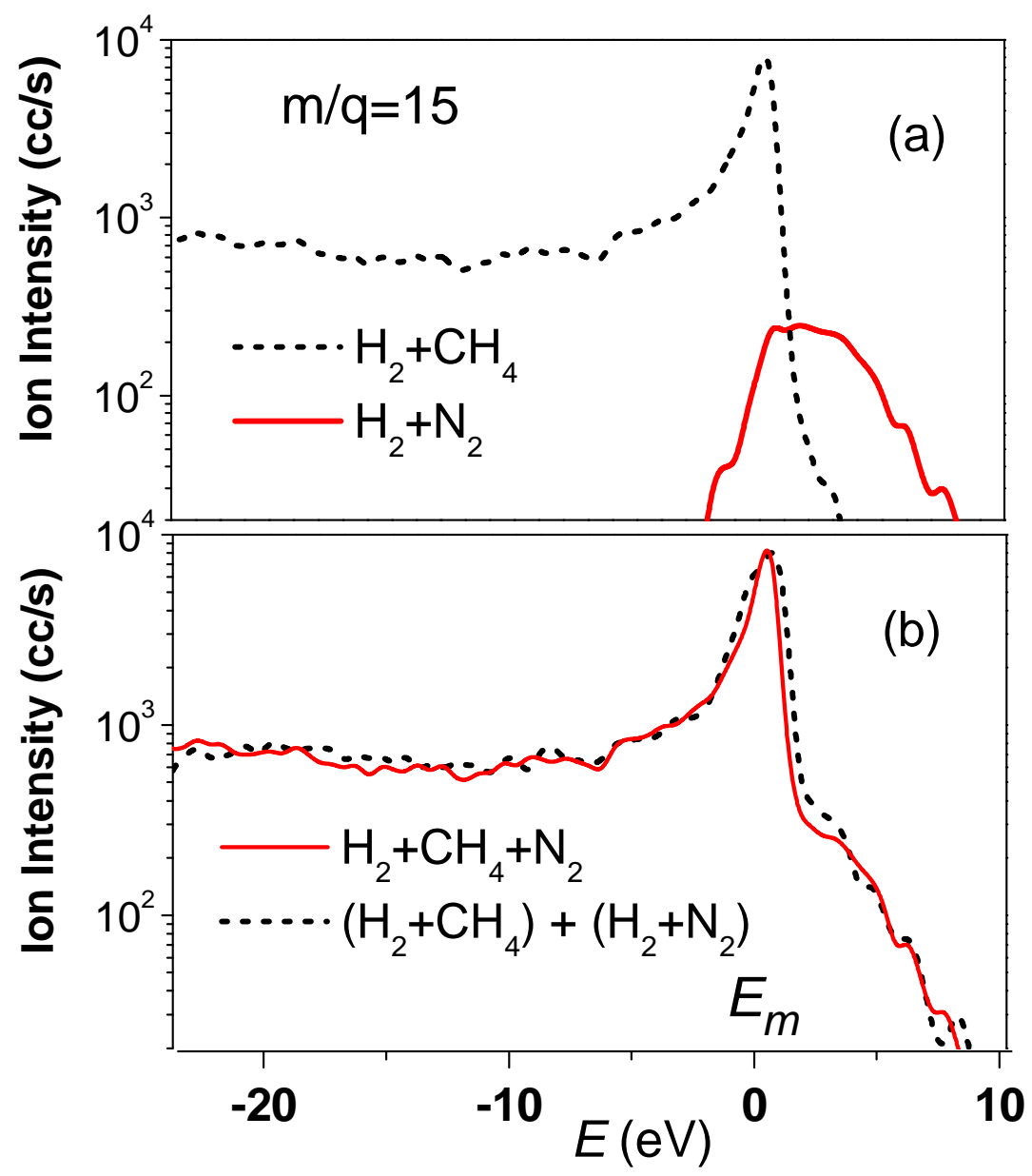

Figure 9 